\title{
Cloud effects on surface energy and mass balance in the ablation area of Brewster Glacier, New Zealand
}

\author{
J. P. Conway ${ }^{1,2}$ and N. J. Cullen ${ }^{1}$ \\ ${ }^{1}$ Department of Geography, University of Otago, Dunedin, New Zealand \\ ${ }^{2}$ Centre for Hydrology, University of Saskatchewan, Saskatoon, Canada \\ Correspondence to: J. P. Conway (jono.conway@otago.ac.nz)
}

Received: 19 January 2015 - Published in The Cryosphere Discuss.: 18 February 2015

Revised: 24 July 2015 - Accepted: 17 November 2015 - Published: 10 February 2016

\begin{abstract}
The effect of clouds on glacier surface energy balance (SEB) has received increased attention in the last decade, but how clouds interact with other meteorological forcing to influence surface mass balance (SMB) is not as well understood. This paper resolves the SEB and SMB at a site in the ablation zone of Brewster Glacier over a 22-month period, using high-quality radiation data to carefully evaluate SEB terms and define clear-sky and overcast conditions. A fundamental change in glacier SEB in cloudy conditions was driven by increased effective sky emissivity and surface vapour pressure, rather than a minimal change in air temperature and wind speed. During overcast conditions, positive net long-wave radiation and latent heat fluxes allowed melt to be maintained through a much greater length of time compared to clear-sky conditions, and led to similar melt in each sky condition. The sensitivity of SMB to changes in air temperature was greatly enhanced in overcast compared to clear-sky conditions due to more frequent melt and changes in precipitation phase that created a strong albedo feedback. During the spring and autumn seasons, the sensitivity during overcast conditions was strongest. To capture these processes, future attempts to explore glacier-climate interactions should aim to resolve the effects of atmospheric moisture (vapour, cloud, and precipitation) on melt as well as accumulation, through enhanced statistical or physically based methods.
\end{abstract}

\section{Introduction}

The response of glaciers to atmospheric forcing is of interest as glaciers are seen as useful scalable proxy records of past climate (e.g. Mölg et al., 2009a) and because the rapid changes occurring in many glaciated regions have implications for both global sea level rise (Kaser et al., 2006) and water resources (e.g. Jost et al., 2012). Reliable attribution of past glacier states and prediction of future ones is dependent on a thorough understanding of the physical processes operating at the glacier surface that link glacier change with climate, that is, the surface mass balance (SMB) and surface energy balance (SEB). For debris-free, mid-latitude glaciers, the SMB is primarily the sum of the relative magnitudes of accumulated solid precipitation and melt. While, in general, incoming short-wave radiation ( $\mathrm{SW} \downarrow$ ) is the major source of energy for glacier melt, variations in SMB are considered to be forced by changes in air temperature and precipitation (Oerlemans, 2005), through both accumulation and melt processes. Reduced solid precipitation often results in an albedo feedback that increases melt; thus increased air temperature can result in enhanced melt if the amount of precipitation that falls as snow decreases. Other mechanisms responsible for the efficient relationship between air temperature and melt vary widely (Sicart et al., 2008), and include the variability of turbulent sensible (QS) and latent (QL) heat fluxes, incoming long-wave radiation ( $\mathrm{LW} \downarrow$ ), and a (somewhat spurious) covariance between air temperature and SW $\downarrow$ in many continental areas. The primary influence of air temperature on melt rate is also modulated by other influences on the SEB such as surface albedo (Oerlemans et al., 2009), humidity (Gillett and Cullen, 2011), and cloud transmission (Pellicciotti et al., 2005).

The strong effect of clouds on glacier SEB has received increased attention in the last decade. Advances in automatic weather station (AWS) deployment on glacier surfaces (Mölg et al., 2009b), the availability of high-quality radiation mea- 
surements (van den Broeke et al., 2004), and development of methods to extract information about cloud cover in data sparse areas (Kuipers Munneke et al., 2011), have allowed the variation of SEB and SMB with cloud cover to be characterized in many areas. Sicart et al. (2010) show that clouds dominate day-to-day variations in $\mathrm{LW} \downarrow$ in mountainous areas while numerous studies detail the fundamental changes in SEB with cloudiness that are often coincident with changes in glacier surface boundary layer (SBL) properties (van den Broeke et al., 2006; Giesen et al., 2008; Gillett and Cullen, 2011). Given their strong control on the SEB, and coincidence with changes in SBL properties it is vital that the role of clouds in altering the sensitivity of SMB to changes in atmospheric state variables (especially air temperature) be assessed.

The glaciers of the Southern Alps of New Zealand occupy a unique position in the westerly wind belt of the Southern Ocean, a region dominated by mid-latitude atmospheric circulation (Tait and Fitzharris, 1998; Ummenhofer and England, 2007). The large barrier the Southern Alps poses to the prevailing winds creates a high precipitation environment, which, coupled to the relatively low elevation of glacier termini (Hoelzle et al., 2007), creates high mass turnover glaciers that have shown high sensitivity to climatic variations in temperature-index glacier modelling studies (Anderson et al., 2006; Oerlemans, 2010). For these reasons the glaciers of the Southern Alps are seen as useful indicators of regional atmospheric circulation in the southwest Pacific and form a vital component of palaeoclimate work (e.g. Lorrey et al., 2007). While a change in precipitation phase and the associated albedo feedback has been shown to be an important component of the sensitivity of SMB to air temperature in New Zealand as in other glaciated regions (Oerlemans 1997; Anderson et al., 2006), there is a suggestion that increased turbulent (mainly sensible) heat fluxes dominate variations in melt (Anderson et al., 2010). This has led some authors to interpret past glacier fluctuations as a linear and direct proxy for regional air temperature (e.g. Putnam et al., 2012), at the exclusion of most other elements of the glacier-climate system.

It has been well established that synoptic-scale processes exert a strong control on the SMB in the Southern Alps, with periods of 20th century glacier advance and retreat associated with anomalies in the regional climate system (Fitzharris et al., 2007). Given that this synoptic variability is closely linked to inferred changes in cloudiness as well as air mass properties (Hay and Fitzharris, 1988), and that these synoptic controls are thought to have varied over palaeoclimatic timescales (Drost et al., 2007; Ackerley et al., 2011), it is vital that the influence of clouds on SMB is separated out from the influence of air mass properties (in particular air temperature). Recent field studies on Brewster Glacier in the Southern Alps, have shown the high frequency of cloudy conditions during all seasons ( $>50 \%$ overcast conditions) as well as the significant and variable effect of clouds on $\mathrm{SW} \downarrow, \mathrm{LW} \downarrow$, and net radiation (Rnet) (Conway et al., 2015). In this context it is timely to examine in detail the influence of clouds on glacier surface climate, SEB, and melt, as well as the manner in which clouds alter the sensitivity of SMB to air temperature in the Southern Alps.

This paper addresses these issues by resolving the SEB and SMB at a site in the ablation zone of Brewster Glacier over a 22-month period in 2010-2012. High-quality surface climate data presented in Cullen and Conway (2015) are used to force an SMB model (Mölg et al., 2008) to estimate both SEB and SMB terms over this period (measurement period). The cloud metrics presented in Conway et al. (2015) are used to identify clear-sky and overcast conditions and thus characterize surface climate, SEB, and melt energy during each condition. To test the sensitivity of SMB to changes in surface climate and radiative components, a more heavily parameterized version of the model is used. This model allows us to separate the effects of changes to surface climate and radiative properties, as well as assess the influence of clouds on the sensitivity. The sensitivity analyses are run using a 2-year time series (sensitivity period) that was constructed from data collected in the measurement period. The following section provides a brief description of the site, data sets, and modelling methods before the results and discussion are presented in subsequent sections.

\section{Methods}

\subsection{Site description and instrumentation}

Brewster Glacier is a small mountain glacier situated in the Southern Alps immediately west of the main divide (Fig. 1). It experiences a temperate maritime high precipitation environment. Annual precipitation is approximately $6000 \mathrm{~mm}$ water equivalent (w.e.), while the annual air temperature over the glacier surface at $1760 \mathrm{~m}$ a.s.l. is $1.2^{\circ} \mathrm{C}$ (Cullen and Conway, 2015). In comparison to other glaciers in the Southern Alps, it has a somewhat lower average slope $\left(16^{\circ}\right)$ but similar mean and terminus elevation (Hoelzle et al., 2007). As it is located on the main divide with relatively high exposure to synoptic weather systems, at the midpoint of the north-south distribution of glaciers in the Southern Alps (Chinn et al., 2012), it is likely to experience the atmospheric controls on SMB that affect the Southern Alps in general.

Data from an automatic weather station (AWS) situated in the ablation area of Brewster Glacier ( $\mathrm{AWS}_{\text {glacier }}$ ) were used in this study (Fig. 1). Table 1 gives details of instrumentation and annual average surface climate variables at $\mathrm{AWS}_{\text {glacier }}$, while further details of the locality and AWS instrumentation can be found in Cullen and Conway (2015). Measurements at $\mathrm{AWS}_{\text {glacier }}$ ran for 22 months from 25 October 2010 to 1 September 2012 (inclusive). Air temperature $\left(T_{\mathrm{a}}\right)$ shows a moderate seasonal cycle (with a range of $8^{\circ} \mathrm{C}$ ), and air mass changes appear to override the subdued diurnal range in $T_{\mathrm{a}}$. 
Table 1. Variables measured, sensor specifications, and mean annual values at $\mathrm{AWS}_{\text {glacier }}$ during the study period.

\begin{tabular}{llll}
\hline Variable & Instrument & Accuracy & Mean annual value \\
\hline Air temperature $\left(T_{\mathrm{a}}\right)$ & Vaisala HMP 45AC & $0.3{ }^{\circ} \mathrm{C}$ & $1.2^{\circ} \mathrm{C}$ \\
Relative humidity $(\mathrm{RH})$ & Vaisala HMP 45AC & $3 \%$ & $78 \%$ \\
Wind speed $(U)$ & RM Young 01503 & $0.3 \mathrm{~m} \mathrm{~s}^{-1}$ & $3.3 \mathrm{~m} \mathrm{~s}^{-1}$ \\
Atmospheric pressure $(p)$ & Vaisala PTB110 & $0.5 \mathrm{hPa}$ & $819 \mathrm{hPa}$ \\
Incoming short-wave radiation $(\mathrm{SW} \downarrow$ meas & Kipp and Zonen CNR4 & $5 \%$ a & $140 \mathrm{~W} \mathrm{~m}^{-2}$ \\
Outgoing short-wave radiation $(\mathrm{SW} \uparrow)$ & Kipp and Zonen CNR4 & $5 \%$ a & $93 \mathrm{~W} \mathrm{~m}^{-2}$ \\
\hline Incoming long-wave radiation $(\mathrm{LW} \downarrow$ meas & Kipp and Zonen CNR4 & $5 \%$ a & $278 \mathrm{~W} \mathrm{~m}^{-2}$ \\
Surface temperature $\left(T_{\mathrm{S}}\right)$ & Kipp and Zonen CNR4 & $1{ }^{\circ} \mathrm{C}^{\mathrm{b}}$ & $-2.7^{\circ} \mathrm{C}^{\mathrm{a}}$ \\
Precipitation $\left(P_{\text {scaled }}\right)^{\mathrm{c}}$ & TB4+Scaled & $25 \% \mathrm{c}$ & $6125 \mathrm{~mm}^{\mathrm{c}}$ \\
Surface and sensor height & SR50a & $\pm 1 \mathrm{~cm}$ & $\mathrm{NA}$ \\
\hline
\end{tabular}

a Uncertainty is estimated to be less than the manufacturer's specifications as noted in van den Broeke et al. (2004) and Blonquist et al. (2009).

$\mathrm{b}$ Based on a $5 \mathrm{~W} \mathrm{~m}^{-2}$ uncertainty in outgoing long-wave radiation.

${ }^{\mathrm{c}}$ From $\mathrm{AWS}_{\text {lake }}$ during snow-free period only. $P_{\text {scaled }}$ is based on scaled relationship between $\mathrm{AWS}_{\text {lake }}$ and a lowland station $(\mathrm{Cullen}$ and Conway, 2015). Uncertainty is estimated from fit of scaled relationship.

Wind speed $(U)$ is moderate with a persistent down-glacier flow despite the small fetch and exposed location (Conway, 2013). Humidity is high with average vapour pressure $\left(e_{\mathrm{a}}\right)$ exceeding that of a melting surface for 4 months during summer. Cloud cover is frequent and associated with onglacier wind direction (Conway et al., 2015). Annual mass balance in the vicinity of AWS glacier is generally negative, despite the large accumulation (> $3 \mathrm{~m}$ w.e.) of winter snowfall during May to September. The significant annual ablation (> 4 m w.e.) generally starts during October, exposing an ice surface in early January and continuing till April or later.

\subsection{Data treatment and cloud metrics}

Cullen and Conway (2015) describe the treatment of the AWS data in detail but a summary of the main steps is given here. Raw $T_{\mathrm{a}}$ data were corrected for the overestimation of $T_{\mathrm{a}}$ measured in the unaspirated shields during times of high solar radiation and low wind speed. This resulted in a mean correction to the original data set of $-0.7^{\circ} \mathrm{C}$. To facilitate SMB modelling, a continuous precipitation data set $\left(P_{\text {scaled }}\right)$ was constructed by comparing summer rain gauge observations from a second AWS situated in the pro-glacial area $\left(\mathrm{AWS}_{\text {lake }}\right)$ to a nearby lowland rain gauge $\left(R^{2}=0.9\right.$ at a daily level).

To construct a high temporal resolution record of observed SMB, surface height observed using a sonic ranger (Cullen and Conway, 2015) was combined with periodic snow density measurements. Snow pits near the start of snowmelt indicated a consistent density approaching $500 \mathrm{~kg} \mathrm{~m}^{-3}$ during late October $\left(443 \mathrm{~kg} \mathrm{~m}^{-3}\right.$ on 23 October $2010 ; 483 \mathrm{~kg} \mathrm{~m}^{-3}$ on 27 October 2011), while density during midwinter was more moderate $\left(320 \mathrm{~kg} \mathrm{~m}^{-3}\right.$ on 18 July 2011$)$. Thus, while the density of melting snow during spring is relatively well constrained, the increasing density due to subsurface pro- cesses (e.g. viscous compaction and melt - refreezing) during the winter months produces some uncertainty in the relationship between surface height and SMB. Beyond the snow-ice transition in early January, a standard ice density of $900 \mathrm{~kg} \mathrm{~m}^{-3}$ was assumed, while short periods of new snowfall were assigned a fresh snow density of $300 \mathrm{~kg} \mathrm{~m}^{-3}$ (Gillett and Cullen, 2011).

The long-wave equivalent cloudiness $(N \varepsilon)$ used in this study was determined from measurements of $\mathrm{LW} \downarrow$ and theoretical upper (overcast) and lower (clear-sky) values of $L W \downarrow$ that are based on surface level meteorological variables, a method that has been used successfully in other glaciated areas (van den Broeke et al., 2006; Giesen et al., 2008). The data set and specific methods used are presented in Conway et al. (2015), but a brief summary is given below. At each half-hourly interval a theoretical upper limit for LW $\downarrow$ is set by applying the Stefan-Boltzmann law to the observed $T_{\mathrm{a}}$ and an emissivity of 1 . A lower limit is set using the clearsky model of Konzelmann (1994), which has both $T_{\mathrm{a}}$ and $e_{\mathrm{a}}$ as dependent variables. These two curves are assumed to represent the minimum and maximum $\mathrm{LW} \downarrow$ at a given $T_{\mathrm{a}}$ and $e_{\mathrm{a}}$, corresponding to cloudiness values of 0 and 1 , respectively. By assuming that cloudiness increases linearly between these minimum and maximum values, $N \varepsilon$ is then calculated from measured $T_{\mathrm{a}}, e_{\mathrm{a}}$ and LW $\downarrow$ at each half-hourly interval. Following Giesen et al. (2008), clear-sky conditions are defined when cloudiness values are smaller than 0.2 and overcast conditions are defined as cloudiness values larger than 0.8 .

The inclusion of $e_{\mathrm{a}}$, as well as $T_{\mathrm{a}}$, as a dependent variable in the calculation of theoretical clear-sky LW $\downarrow$ was necessary, as clear-sky $L W \downarrow$ is strongly dependent on both variables at this temperate location (Durr and Philipona, 2004; Conway et al., 2015). The effect of this is to include a larger proportion of days in the clear-sky category, as some clear-sky days with high $e_{\mathrm{a}}$ (and $\mathrm{LW} \downarrow$ ) would have been excluded had 


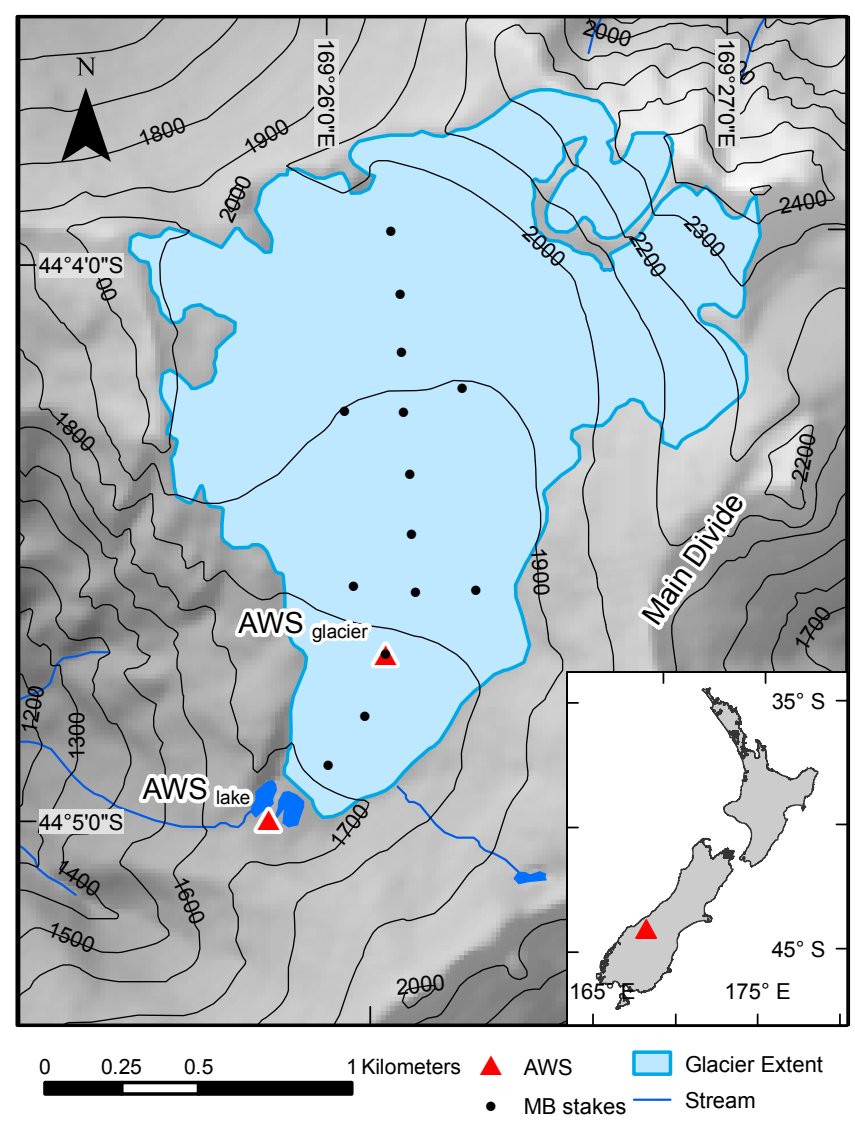

Figure 1. Map of Brewster Glacier showing AWS locations and surrounding topography. Contour lines are at $100 \mathrm{~m}$ intervals. Longterm mass-balance network (MB stakes) shown as filled circles. The glacier margin shown is based on a 1997 GPS survey (Willis et al., 2009). The ridgeline to the southeast of the glacier is the main divide of the Southern Alps. The inset map shows the location of Brewster Glacier within New Zealand.

only $T_{\mathrm{a}}$ been used in the calculation of clear-sky LW $\downarrow$. A comparison to cloudiness derived from incoming short-wave measurements gave a correlation coefficient of 0.89 and a root-mean-square difference (RMSD) of 0.19 (Conway et al. 2015), suggesting the method is a satisfactory approach to assess cloudiness at this site.

Though not directly comparable to traditional cloud fraction metrics based on manual or sky camera observations, $N \varepsilon$ effectively characterizes the impacts of clouds on surface radiation fluxes. It also has the advantage over metrics based on $\mathrm{SW} \downarrow$, in that it provides $24 \mathrm{~h}$ coverage and is not affected by solar zenith angle or multiple reflections between the surface and atmosphere.

\subsection{Model description}

An SMB model (Mölg et al., 2008) was used to resolve surface energy and mass fluxes at $\mathrm{AWS}_{\text {glacier }}$ for the full 22month study period. A full description of the model is given in Mölg et al. (2008, 2009a), but a short description of the parameterization of each term is given here. The model computes SMB as the sum of snow accumulation, melt, refreezing of liquid water in the snowpack, and mass fluxes of water vapour (deposition and sublimation), while surface temperature $\left(T_{\mathrm{S}}\right)$ is less than $273.15 \mathrm{~K}$. Fluxes of vapour while the surface is melting are not included directly in the SMB, as condensation and evaporation add and remove mass from the liquid meltwater at the surface, respectively. The model uses $T_{\mathrm{S}}$ as a free variable to close the SEB (Eq. 1) at each $30 \mathrm{~min}$ time step:

$$
\begin{aligned}
\mathrm{QM} & =\mathrm{SW} \downarrow(1-\alpha)+\mathrm{LW} \downarrow \\
& -\sigma \varepsilon T_{\mathrm{s}}^{4}+\mathrm{QS}+\mathrm{QL}+\mathrm{QR}+\mathrm{QC},
\end{aligned}
$$

where QM is the energy for surface melt while $T_{\mathrm{S}}=273.15 \mathrm{~K}, \mathrm{SW} \downarrow$ is the incoming solar radiation, $\alpha$ is the albedo, $\mathrm{LW} \downarrow$ is the incoming long-wave radiation, $\sigma$ is the Stefan-Boltzman constant $\left(5.67 \times 10^{-8} \mathrm{~W} \mathrm{~m}^{-2}\right), \varepsilon$ is the emissivity of snow/ice (equal to unity), QS and QL are the turbulent sensible and latent heat fluxes, respectively, $\mathrm{QR}$ is the rain heat flux, and QC is the conductive heat flux through the glacier subsurface. The convention used is that energy fluxes directed towards the surface are positive.

Two different configurations of the model are presented in this paper, distinguished only by their treatment of surface radiation fluxes. For the first, SEBmr, we used measured values of $S W \downarrow, L W \downarrow$, and albedo from $A W S_{\text {glacier }}$ (Table 2) to provide best estimates of SEB and SMB terms for analysis over the measurement period. For the second, SEBpr, we used parameterized radiation fluxes (Table 2) to assess the sensitivity of the SMB to changes in surface climate (detailed further in Sect. 2.5). All other energy fluxes are calculated consistently between configurations. QR is calculated using $P_{\text {scaled }}$, assuming rain temperature is equal to $T_{\mathrm{a}}$. New snow was calculated from $P_{\text {scaled }}$ using a rain/snow threshold $\left(T_{\mathrm{r} / \mathrm{s}}\right)$ of $1{ }^{\circ} \mathrm{C}$ and a fixed density of $300 \mathrm{~kg} \mathrm{~m}^{-3}$. The iterative SEB closure scheme of Mölg et al. (2008) was used to calculate $T_{\mathrm{s}}$, with QC being calculated as the flux between the surface and the top layer of the 12-layer subsurface module (subsurface levels: 0.1, 0.2, 0.3, 0.4, 0.5, 0.8, 1.4, 2, 3, 5, and $7 \mathrm{~m}$ ). Penetrating short-wave radiation was not included in the model, as the subsurface temperature profile was not measured throughout the study period; hence the optimization of a penetrating short-wave radiation scheme would be subject to large uncertainty. The depth, density, and temperature (isothermal at $0^{\circ} \mathrm{C}$ ) of the snowpack was prescribed at the start of the measurement period from snow-pit measurements (see Sect. 2.2), while the bottom temperature in the subsurface module was held fixed at $0^{\circ} \mathrm{C}$.

The turbulent heat fluxes, QS and QL, were calculated using a bulk-aerodynamic approach using the $C_{\log }$ parameterization as described by Conway and Cullen (2013). The roughness lengths for momentum $\left(z_{0 v}\right)$, temperature $\left(z_{0 t}\right)$, and humidity $\left(z_{0 q}\right)$ over an ice surface at 
Table 2. Configuration of SEBmr and SEBpr, showing input data and references used in the calculation of radiation terms in each configuration.

\begin{tabular}{lll}
\hline Variable & Model version & Reference and/or input data \\
\hline$\alpha$ & SEBmr & Accumulated albedo; van den Broeke et al. (2004) \\
& SEBpr & Oerlemans and Knap (1998) $\left(P_{\text {scaled }}, T_{\mathrm{a}}\right)$ \\
\hline $\mathrm{SW} \downarrow$ & $\mathrm{SEBmr}$ & $\mathrm{SW} \downarrow_{\text {surface }}$ \\
& $\mathrm{SEBpr}$ & Conway et al. (2015) $\left(N_{\varepsilon}, T_{\mathrm{a}}, \mathrm{RH}\right)$ \\
\hline $\mathrm{LW} \downarrow$ & $\mathrm{SEBmr}$ & $\mathrm{LW} \downarrow$ meas \\
& $\mathrm{SEBpr}$ & Conway et al. (2015) $\left(N_{\varepsilon}, T_{\mathrm{a}}, \mathrm{RH}\right)$ \\
\hline
\end{tabular}

Table 3. Input parameter uncertainty introduced in Monte Carlo simulations of SMB uncertainty.

\begin{tabular}{|c|c|c|c|}
\hline Input parameter & Value(s) & Systematic (random) error & Model \\
\hline Roughness length for momentum $\left(z_{0 v}\right)^{\mathrm{a}}$ & $3.6 \times 10^{-3} \mathrm{~m}$ & $z_{0 v} \times 10$ NORMRND $(0,0.274)$ & SEBmr, pr \\
\hline Rain/snow threshold $\left(T_{\mathrm{r} / \mathrm{s}}\right)^{\mathrm{b}}$ & $1.0^{\circ} \mathrm{C}$ & $0.3(0.5)$ & SEBmr, pr \\
\hline Albedo of surface $\left(\alpha_{\text {snow }}, \alpha_{\text {firn }}, \alpha_{\text {ice }}\right)^{b}$ & $0.95\left(\alpha_{\text {snow }}\right) 0.65\left(\alpha_{\text {firn }}\right) 0.42\left(\alpha_{\text {ice }}\right)$ & 0.05 & SEBpr \\
\hline Constant for cloud extinction coefficient ${ }^{\mathrm{c}}$ & 0.1715 & $0.0048(0.0048)$ & SEBpr \\
\hline Multiplier for cloud extinction coefficient ${ }^{\mathrm{c}}$ & $0.07182 \mathrm{hPa}^{-1}$ & $0.0324(0.0324)$ & SEBpr \\
\hline Albedo of surrounding terrain ${ }^{\mathrm{d}}$ & 0.45 & 0.1 & SEBpr \\
\hline Clear-sky emissivity constant $\mathrm{t}^{\mathrm{e}}$ & $0.456 \mathrm{~Pa}^{-1} \mathrm{~K}$ & $0.0204(0.0204)$ & SEBpr \\
\hline
\end{tabular}

a Standard deviation of $z_{0 v}$ (Conway and Cullen, 2013). NORMRND is a MATLAB function that selects a random number from a normal distribution with mean of 0 and standard deviation of 0.274 ;

b Machguth et al. (2008);

c $95 \%$ confidence interval of optimized coefficients (Conway et al., 2015). Limited to 0.95

d Assumed; no random errors as terrain albedo will not vary at this timescale ( $30 \mathrm{~min})$;

e RMSD of clear-sky values (Conway et al., 2015).

$\mathrm{AWS}_{\text {glacier }}$ are well constrained by in situ measurements $\left(z_{0 v}=3.6 \times 10^{-3} \mathrm{~m}, z_{0 t}=z_{0 q}=5.5 \times 10^{-5} \mathrm{~m}\right.$; Conway and Cullen, 2013), though spatial and temporal variability is still probable. A further period of eddy covariance measurements over a spring snow surface (27 October to 3 November 2011) showed a log-mean value for $z_{0 v}$ of $1.8 \times 10^{-3} \mathrm{~m}$ $\left(\sigma=1.3 \times 10^{-2} \mathrm{~m}, n=31\right)$, using the same filtering criterion as Conway and Cullen (2013). No reliable estimates of $z_{0 t}$ or $z_{0 q}$ were possible because of the large uncertainties involved with the small temperature and vapour pressure gradients experienced during this period. Given the similar, but more uncertain, $z_{0 v}$ over snow and the large effect of $z_{0 t}$ on the effective roughness length which tends to counter a change in $z_{0 v}$ (Conway and Cullen, 2013), roughness lengths derived over ice were adopted for the entire period.

\subsection{Estimation of uncertainty using a Monte Carlo approach}

To estimate uncertainty in modelled SMB, a series of Monte Carlo simulations were made covering the range of input data and parameter uncertainty expected for each configuration of the model (SEBmr and SEBpr). Table 3 shows the parameter uncertainty introduced for each configuration, while input data uncertainty was kept consistent with that used in Conway and Cullen (2013) and is given in Table 1. For both configurations, 5000 runs of the measurement period were made, with systematic and random errors being assigned to each input variable before each simulation and time step, respectively. Errors were calculated by multiplying the uncertainties associated with each input variable (Tables 1 and 3 ) by normally distributed random numbers $(\mu=0 ; \sigma=1)$, with the exception of $z_{0 v}$ which was logarithmically transformed before the uncertainty was applied. The $5000 \mathrm{SMB}$ time series computed for each configuration were subjected to a first-order check, using measured $T_{\mathrm{s}}$ as a proxy for a realistic simulation of the SEB. Runs were removed when 30 min modelled $T_{\mathrm{S}}$ had an RMSD $>1.5 \mathrm{~K}$ or $R^{2}<0.9$, which removed $\sim 10 \%$ of runs from each ensemble. The remaining runs were then used to compute an ensemble mean and standard deviation for the SMB accumulated over 1-day and 10day periods in addition to the full measurement period. Runs that did not correctly predict the accumulated SMB at the end of the measurement period were not removed, as it was unknown if any systematic errors would remain constant over the study period. Thus, the model uncertainty over a shorter time period (e.g. 1 or 10 days) was kept independent of the final "correct" accumulated SMB. 


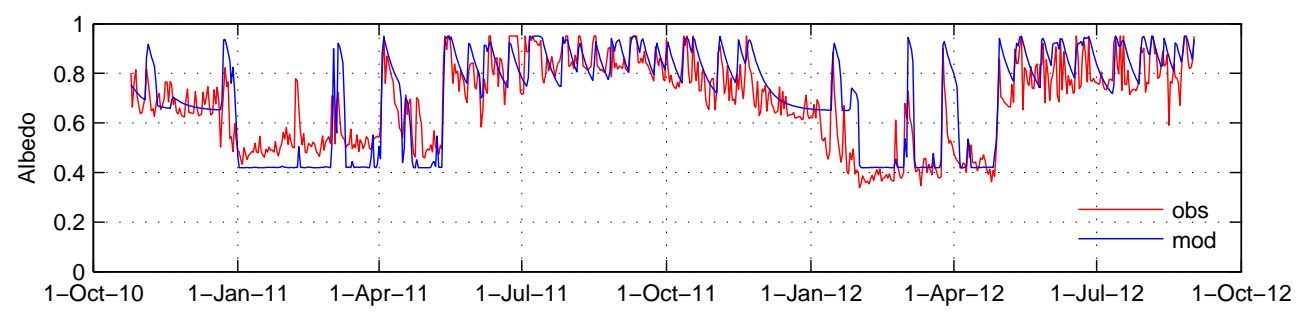

Figure 2. Daily average albedo observed at $\mathrm{AWS}_{\text {glacier }}$ (red) during the measurement period and modelled in SEBpr (blue) using the expressions of Oerlemans and Knap (1998), with locally optimized coefficients.

\subsection{Mass-balance sensitivity configuration}

To assess the mass-balance sensitivity $(\triangle \mathrm{SMB})$ at $\mathrm{AWS}_{\text {glacier, }}$ further runs were made with the SEBpr configuration using a hybrid 2-year data set (sensitivity period). The goal was not only to show the extent to which elements of the climate system could force SMB changes but also to understand how uncertainty in model input data or parameterization impacted estimates of SMB. Because the measurement period started in spring, the initial depth and density of the snowpack was prescribed in these runs. However, a realistic evolution of snow depth with perturbations in surface climate (especially $T_{\mathrm{a}}$ ) is required to assess $\triangle \mathrm{SMB}$, i.e. $\triangle \mathrm{SMB}$ is assessed with accumulation seasons preceding ablation seasons. To this end, a hybrid 2-year data set was constructed using data from $\mathrm{AWS}_{\text {glacier }}$ by rearranging the measurement period time series. The particular periods used were (in order) 1 May to 1 September 2012, 2 September to 24 October 2011, and 25 October 2010 to 30 April 2012. This gave two full SMB seasons (1 May-30 April) in sensitivity runs and retained variability in the input data without relying on data from off-glacier sources. Fortunately, the snow depth predicted by SEBpr at the end of the first hybrid accumulation season matches that at the start of the measurement period (25 October 2010) so the evolution of snow depth (and albedo) during the remainder of the sensitivity run is comparable with that in the measurement period.

To enable the amount of solid precipitation to alter albedo within SEBpr, albedo was simulated using the parameterization of Oerlemans and Knap (1998). This scheme computes albedo from three values representative of fresh snow $\left(\alpha_{\text {frsnow }}\right)$, firn $\left(\alpha_{\text {firn }}\right)$, and ice $\left(\alpha_{\text {ice }}\right)$, accounting for the evolution of fresh snow to firn through an e-folding constant $(t *)$ which describes the characteristic albedo timescale. Two modifications were made to the scheme (Mölg et al., 2012). Firstly, when new snowfall is removed by melt, the albedo reverts back to the albedo of the underlying surface. Secondly, a daily total snowfall in excess of $5 \mathrm{~cm}$ (depth) was introduced as a threshold above which the new snowfall impacts albedo, as small snowfall is most likely redistributed into crevasses and hollows on the glacier surface, where it will have a minimal impact on the albedo.
An analysis of measured albedo $\left(\alpha_{\text {acc }}\right)$ at $\mathrm{AWS}_{\text {glacier }}$ allowed local values of $\alpha_{\text {frsnow }}(0.95), \alpha_{\text {firn }}(0.65)$, and $\alpha_{\text {ice }}$ (0.42) to be defined (Fig. 2). The higher local values are likely indicative of lower levels of contaminants that are responsible for reduced albedo at other sites (Oerlemans et al., 2009) and a lack of debris surrounding Brewster Glacier. A better fit to the evolution of measured albedo was also found by decreasing $t^{*}$ to 10 days, which seems reasonable given the higher rate of melt (and therefore snow metamorphism) in this maritime environment. Figure 2 also shows a marked difference in ice surface albedo between the two seasons. It is unclear if this difference reflects changes over a large spatial scale or if a localized increase in sediment observed in the vicinity of AWS glacier $_{\text {during the summer of } 2012 \text { contributed }}$ to the decrease in albedo during the second season. Without a clear basis for this variation, a mean value of $\alpha_{\text {ice }}=0.42$ was adopted for both seasons.

The value of $\triangle \mathrm{SMB}$ was computed by conducting runs with SEBpr over the sensitivity period, introducing a range of systematic perturbations to input data and parameters (introduced in Sect. 3.4) and comparing SMB between each run. To calculate variations in $\triangle \mathrm{SMB}$ with cloudiness, $\triangle \mathrm{SMB}$ was computed at each model time step (i.e. $\mathrm{mm}$ w.e. $30 \mathrm{~min}^{-1}$ ) for each perturbation run. Model time steps were then selected based on cloudiness $\left(N_{\varepsilon}\right)$ and a monthly average produced for clear-sky and overcast conditions. For ease of interpretation, $\triangle \mathrm{SMB}$ was converted to a daily rate (mm w.e. day ${ }^{-1}$ ) by multiplying half-hourly $\triangle$ SMB by the number of model time steps within a day (48). By definition, the sum of $\triangle \mathrm{SMB}$ for each time step within a year is equal to the accumulated $\triangle \mathrm{SMB}$ of the entire year, which is the more commonly reported value (e.g. $1.5 \mathrm{~m}$ w.e. $\mathrm{yr}^{-1}$ ).

\section{Results}

\subsection{Model evaluation}

Both configurations of the SMB model (SEBmr and SEBpr) were validated against observed $T_{\mathrm{S}}$ and SMB during the measurement period. Modelled $T_{\mathrm{S}}$ from reference runs of both configurations agreed well with $T_{\mathrm{s}}$ calculated from measurements of outgoing long-wave radiation (Fig. 3). Errors at 


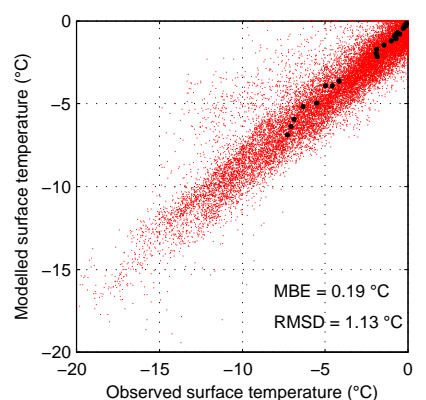

(a) SEBmr

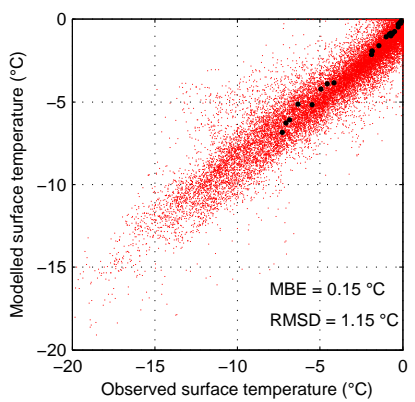

(b) SEBpr

Figure 3. Observed versus modelled surface temperature for (a) SEBmr and (b) SEBpr runs. Red dots are 30 min averages, while black dots are monthly averages.

Table 4. Observed and modelled SMB ( $\mathrm{m}$ w.e) for selected periods between stake measurements in ablation (Abl) and accumulation (Acc) seasons. Figure 4 shows the length of each period.

\begin{tabular}{lrrr}
\hline Period & Observed & SEBmr & SEBpr \\
\hline Abl1 snow & -1.74 & -1.78 & -1.67 \\
Abl1 ice & -3.35 & -2.92 & -3.28 \\
Acc1 & 1.52 & 1.40 & 1.46 \\
Abl2 snow & -1.51 & -1.78 & -1.48 \\
Abl2 ice & -1.94 & -1.87 & -1.66 \\
\hline
\end{tabular}

the 30 min time step were comparable to other studies (van den Broeke et al., 2011), and monthly averages indicated no seasonally dependent errors in the SEB. Both configurations successfully simulated the large accumulation and ablation observed at $\mathrm{AWS}_{\text {glacier }}$ during the measurement period (Fig. 4). SMB during the first accumulation season was within $\pm 10 \%$ of that observed (Table 4), which was encouraging given the uncertainties in the scaled precipitation data set and rain/snow threshold. SEBmr showed small discrepancies in modelled ablation (around 10\%) for the ice surface in the first season and the snow surface in the second season (Table 4). SEBpr showed a similar performance, with an underestimate of ablation for the ice surface in the second season likely related to the lower albedo observed during this season (Fig. 4). Despite these small deviations, both configurations produced SMBs over the two seasons that were well within the accumulated uncertainty due to measurement and parameter errors (grey shading in Fig. 4). The small discrepancies between modelled and observed ablation could have been removed, perhaps through specifying different $z_{\text {ov }}$ for snow and ice surfaces. However, given that the deviations were not consistent between each season and model, both models exhibited large accumulated uncertainty, and our interest was primarily at shorter timescales, we found no strong reasoning for tuning model parameters to fit model values precisely.

We also compared SMB over 1-day and 10-day periods to ensure we could correctly simulate the large temporal variability in accumulation and ablation with each configuration of the model (Fig. 5). SEBmr effectively captured the large variability in SMB during both accumulation and ablation seasons with maximum 10-day ablation and accu-

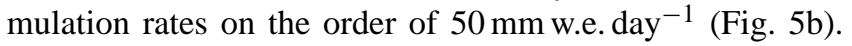
A consistent bias in ablation was not observed, confirming our decision not to tune modelled melt exactly over the season. The significant number of large daily ablation events (> $50 \mathrm{~mm}$ w.e. day ${ }^{-1}$ ) observed in the ablation record were, in general, captured by SEBmr (Fig. 5a). If anything, a bias toward under-prediction of these events was seen. This bias is likely related to an under-prediction of $\mathrm{QR}$, as the timeaveraging $P_{\text {scaled }}$ underestimated the very intense rainfall rates $\left(>100 \mathrm{~mm} \mathrm{day}^{-1}\right)$ associated with the largest ablation events (Gillett and Cullen, 2011). The 10-day accumulation rates were captured well, while daily totals exhibited larger scatter, reflecting the difficulty of determining observed winter SMB from surface height records as well as the large combined uncertainty due to $P_{\text {scaled }}, T_{\mathrm{a}}$, and $T_{\mathrm{r} / \mathrm{s}}$. The good agreement of modelled and observed SMB at these short temporal resolutions suggests SEBmr is able to capture the variations in melt and accumulation forced by the key synoptic atmospheric controls.

SEBpr showed similar agreement to observed SMB at both daily and 10-day level (Fig. 5c, d). The larger uncertainty in modelled ablation was expected given the uncertainties involved in parameterizing incoming radiation fluxes and albedo. A positive bias in modelled ablation rates was exhibited, though the $1: 1$ line is still well within the model uncertainty $(2 \sigma)$. This bias was likely an artefact of the limited value of the cloud extinction coefficient $(k)$, which produced a positive bias in ensemble mean SW $\downarrow$ as compared to the reference run (not shown). However, this bias was of less concern as the remaining analysis used the reference run and not the ensemble mean from the Monte Carlo runs to explore cloud effects on SMB and $\triangle \mathrm{SMB}$. That the temporal variability of SMB was effectively captured by SEBpr gives us confidence that this configuration captures the same atmospheric controls on SMB as SEBmr and as such provides a reliable and useful tool for sensitivity analysis.

\subsection{Variation of SBL climate with cloudiness}

The seasonal variation of surface climate in both clear-sky and overcast conditions during the measurement period is shown in Fig. 6a, b. Air temperature exhibited a clear but relatively small $\left(\sim 8^{\circ} \mathrm{C}\right)$ seasonal cycle and was only slightly lower in overcast conditions compared to clear-sky conditions (Table 5). Vapour pressure was significantly higher in overcast conditions, due to the combination of high relative humidity $(\mathrm{RH})$ with only slightly lower mean air temperature. Consequently in overcast conditions, mean $e_{\mathrm{a}}$ was above the saturated vapour pressure of a melting snow/ice 


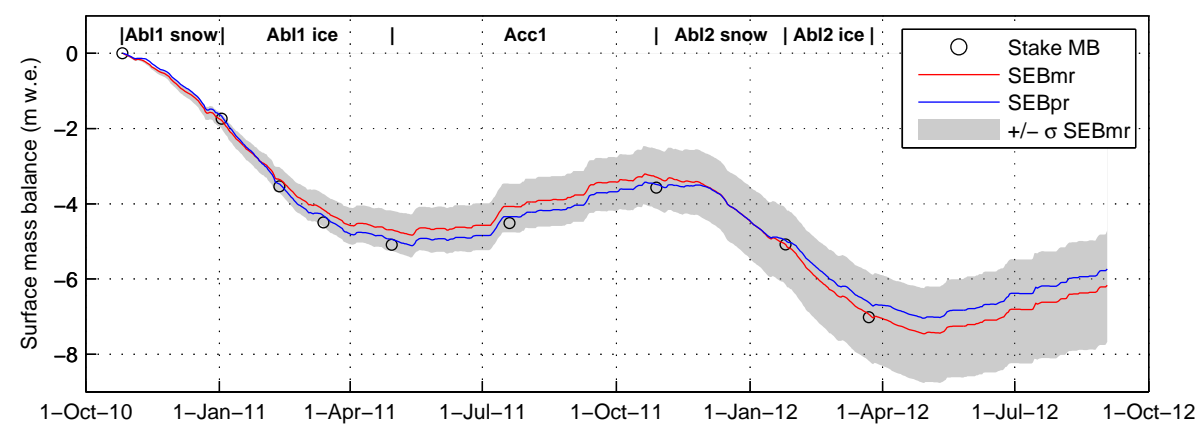

Figure 4. Accumulated SMB during the measurement period as modelled by the reference runs of SEBmr and SEBpr. The points give observed mass balance from periodic stake and snow-pit measurements. The SMB for selected ablation and accumulation periods (shown as Abl1 snow etc.) are given in Table 4. The shaded envelope shows \pm 1 standard deviation from the mean of SEBmr, calculated using Monte Carlo simulations (see Sect. 2.4 for details).

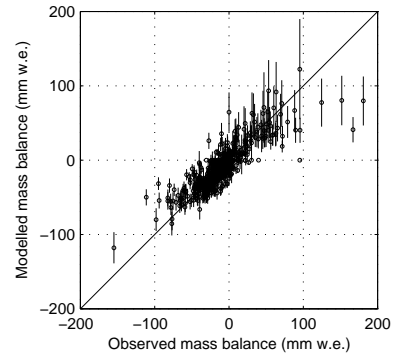

(a) SEBmr: Daily totals

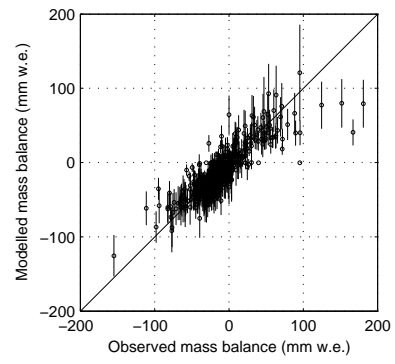

(c) SEBpr: Daily totals

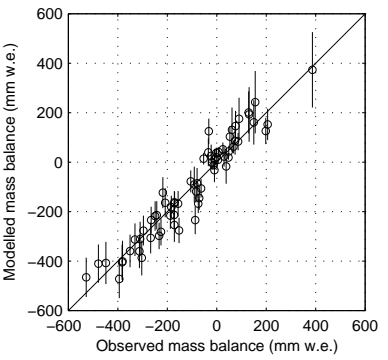

(b) SEBmr: 10-day totals

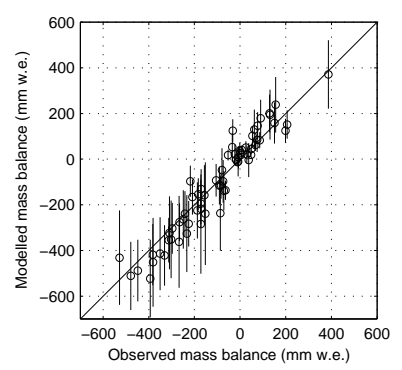

(d) SEBpr: 10-day totals

Figure 5. Observed versus modelled mass balance for (a, b) SEBmr and (c, d) SEBpr over 1-day and 10-day periods. Error bars show $\pm 2 \sigma$ from the ensemble mean values. The solid diagonal line is a $1: 1$ line.

surface $(6.11 \mathrm{hPa})$ during December to April, while in clearsky conditions mean $e_{\mathrm{a}}$ only reached this condition during February. Average $T_{\mathrm{S}}$ exhibited pronounced differences, being significantly higher in overcast conditions during every month. Average wind speed $(U)$ was somewhat higher $(0.1$ to $0.7 \mathrm{~m} \mathrm{~s}^{-1}$ ) in overcast conditions during most of the ablation season, while only small or non-significant differences with cloudiness were noted in other seasons (Table 5). Thus, the main changes in surface climate observed during cloudy periods were an increase in $e_{\mathrm{a}}$, which, despite slightly lower $T_{\mathrm{a}}$, were accompanied by a large increase in $T_{\mathrm{s}}$.

\subsection{Variation of SEB and melt with cloudiness}

Monthly average SEB terms diagnosed using SEBmr showed marked variation with cloudiness and season during the measurement period (Fig. 6c, d). Clear-sky conditions were characterized by large and opposing fluxes. SWnet dominated the seasonal cycle, provided the largest source of energy during the summer months, and peaked after the summer solstice in response to decreased albedo associated with the transition from a snow to ice surface in early January. LWnet remained a large sink throughout the year, creating strongly negative Rnet during the winter months (JJA) that was responsible for cooling the glacier surface. Low $T_{\mathrm{s}}$ in clear-sky conditions allowed QS to remain directed towards the surface throughout the year. QS was of a similar magnitude to LWnet and peaked during the winter months in response to an increase in both $U$ and the surface-air temperature gradient (Fig. 6a, b). QL was much smaller in magnitude than QS and of a generally negative sign, indicating that during clear skies, sublimation or evaporation dominated over deposition or condensation. QR was absent and positive QC indicated that nocturnal cooling of the surface and subsurface was occurring. QM in excess of $20 \mathrm{~W} \mathrm{~m}^{-2}$ (equivalent to $5 \mathrm{~mm}$ w.e. day ${ }^{-1}$ ) was present for a 7-month period between October and April (inclusive). In general the seasonal cycle of QM followed that of SWnet, but was modulated by variations in QL and QS.

In contrast, average energy terms in overcast conditions were smaller in magnitude and directed towards the surface (Fig. 6d). SWnet was still the largest source of energy to the surface. LWnet was positive through most of the year, due to the enhancement of $\mathrm{LW}_{\downarrow}$ by low cloud cover and $T_{\mathrm{S}}$ being limited to $0^{\circ} \mathrm{C}$. Consequently, Rnet was positive throughout the year and larger than in clear-sky conditions from March to November. QS and QL were nearly equal in magnitude and both directed towards the surface, together producing a source of energy comparable to the contribution from Rnet. A distinct seasonal cycle in QS and QL was driven by the strong seasonal variation in surface-air temper- 


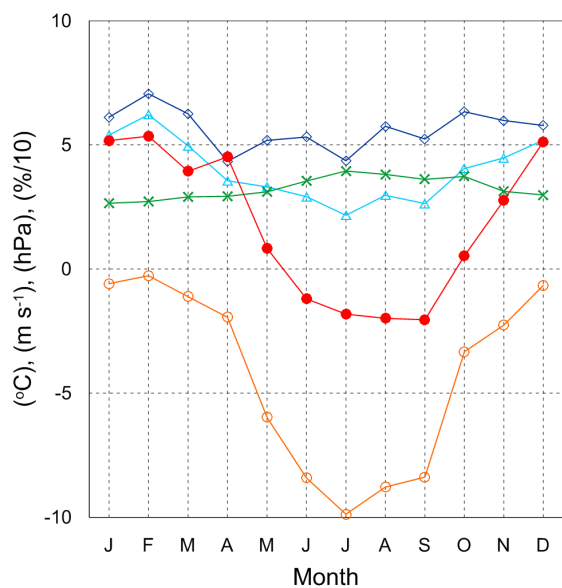

(a) Clear-sky

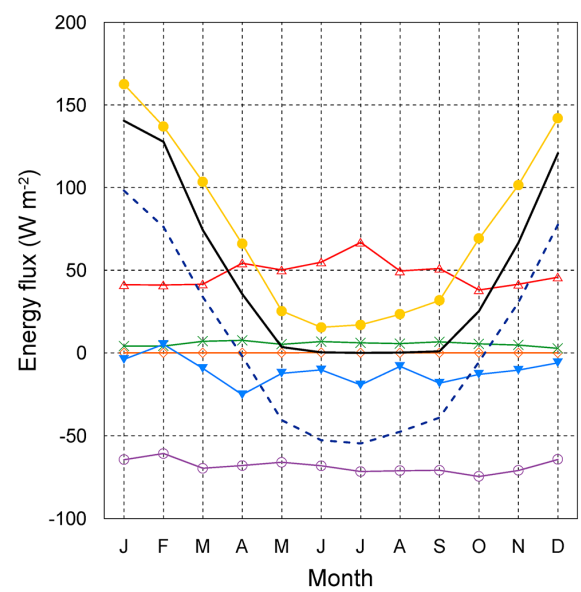

(c) Clear-sky

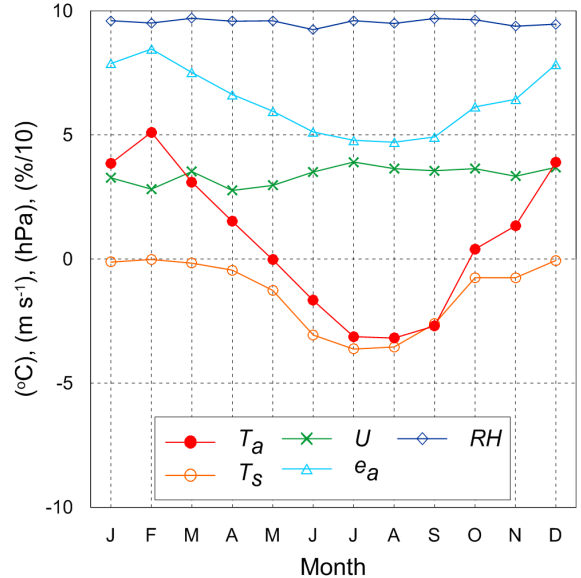

(b) overcast

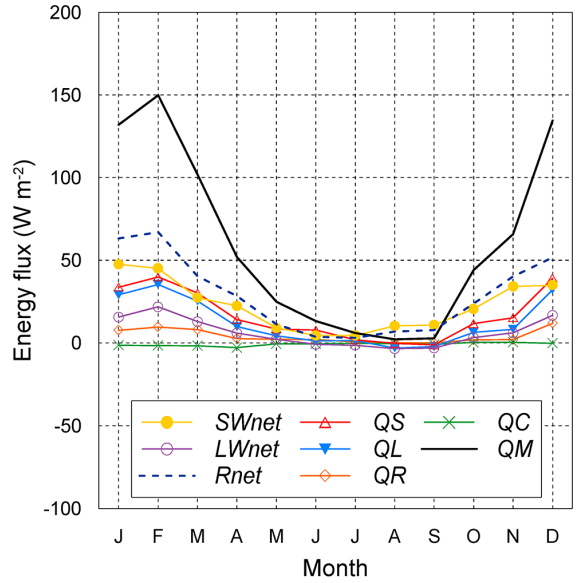

(d) overcast

Figure 6. Monthly mean surface climate $(\mathbf{a}, \mathbf{b})$ and surface energy fluxes $(\mathbf{c}, \mathbf{d})$ at AWS $\mathrm{Alacier}_{\text {in }}(\mathbf{a}, \mathbf{c})$ clear-sky and (b, d) overcast conditions. Partial cloud conditions are a graduation between the two extremes and are not shown for brevity. Surface climate variables include air and surface temperature $\left(T_{\mathrm{a}}\right.$ and $\left.T_{\mathrm{s}} ;{ }^{\circ} \mathrm{C}\right)$, wind speed $\left(U ; \mathrm{m} \mathrm{s}^{-1}\right)$, vapour pressure $\left(e_{\mathrm{a}} ; \mathrm{hPa}\right)$, and relative humidity $(\mathrm{RH})$ on a scale from 0 to 10 (i.e. \% / 10).

Table 5. Mean differences in surface climate between clear-sky and overcast conditions. Positive values indicate an increase in overcast conditions.

\begin{tabular}{|c|c|c|c|c|c|c|c|c|c|c|c|c|c|}
\hline Variable & Jan & Feb & Mar & Apr & May & Jun & Jul & Aug & Sep & Oct & Nov & Dec & Annual \\
\hline$T_{\mathrm{a}}\left({ }^{\circ} \mathrm{C}\right)$ & -1.3 & -0.2 & -0.8 & -3 & -0.9 & -0.5 & -1.3 & -1.2 & -0.7 & -0.1 & -1.4 & -1.2 & -1.1 \\
\hline RH (\%) & 35 & 25 & 35 & 53 & 44 & 39 & 52 & 37 & 45 & 33 & 34 & 37 & 39 \\
\hline$e_{\mathrm{a}}(\mathrm{hPa})$ & 2.5 & 2.2 & 2.5 & 3.1 & 2.6 & 2.2 & 2.6 & 1.7 & 2.3 & 2.1 & 2 & 2.7 & 2.4 \\
\hline$U\left(\mathrm{~m} \mathrm{~s}^{-1}\right)$ & 0.6 & 0.1 & 0.6 & -0.2 & -0.1 & 0 & 0 & -0.2 & -0.1 & -0.1 & 0.2 & 0.7 & 0.1 \\
\hline$T_{\mathrm{S}}\left({ }^{\circ} \mathrm{C}\right)$ & 0.5 & 0.3 & 0.9 & 1.5 & 4.7 & 5.4 & 6.3 & 5.2 & 5.8 & 2.6 & 1.5 & 0.6 & 2.9 \\
\hline$p(\mathrm{hPa})$ & -7 & -4 & -8 & -6 & -10 & -7 & -12 & -4 & -9 & -3 & -7 & -8 & -7 \\
\hline
\end{tabular}

Boldface indicates monthly differences are significant at the $95 \%$ level using a two-sided $t$ test assuming unequal variances. Temperature and wind speed are normalized to $2 \mathrm{~m}$ values.

ature and moisture gradients in overcast conditions (Fig. 6b). QR made a small contribution to QM during the summer and $\mathrm{QC}$ was negligible. The net result was that despite the mod- erate magnitude of individual energy fluxes in overcast conditions, mean QM was similar to values observed in clearsky conditions during most months. The exception was be- 
Table 6. Average surface energy fluxes $\left(\mathrm{W} \mathrm{m}^{-2}\right)$ for melting periods in clear-sky and overcast conditions, all melting periods, and all periods during the measurement period. Numbers in parentheses show the proportion of QM for each condition.

\begin{tabular}{lrrrrrrrr}
\hline & SWnet & LWnet & Rnet & QS & QL & QR & QC & QM \\
\hline Melting + clear-sky periods & $240(121)$ & $-67(-34)$ & $173(87)$ & $39(20)$ & $-7(-3)$ & $0(0)$ & $-6(-3)$ & 199 \\
Melting + overcast periods & $36(33)$ & $15(14)$ & $51(46)$ & $30(27)$ & $24(22)$ & $7(7)$ & $-2(-2)$ & 110 \\
Melting periods & $96(70)$ & $-8(-6)$ & $88(65)$ & $32(24)$ & $15(11)$ & $5(3)$ & $-3(-2)$ & 136 \\
All periods & $49(83)$ & $-27(-46)$ & $22(37)$ & $31(53)$ & $2(3)$ & $2(4)$ & $2(3)$ & 58 \\
\hline
\end{tabular}

Melting conditions are selected as periods where $\mathrm{QM}>0$ in SEBmr.

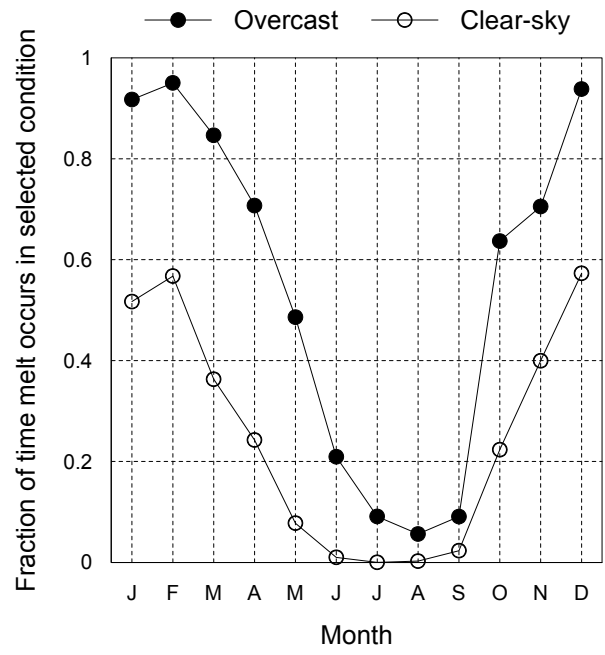

Figure 7. Fraction of time surface melting occurred in clear-sky (open circles) and overcast (closed circles) conditions during each month. Melting conditions are selected as periods where $\mathrm{QM}>0$ in SEBmr.

tween February and May, where QM in overcast conditions exceeded values in clear-sky conditions.

While mean QM was similar in clear-sky and overcast conditions, melting occurred much more frequently in overcast conditions (Fig. 7). Given that day length varies between 11.5 and $15.5 \mathrm{~h}$ during October to April (inclusive) and that melt occurred during 70 to $95 \%$ of overcast conditions, nocturnal melt was a significant feature in overcast conditions during these months. While clear-sky and overcast conditions accounted for 36 and $45 \%$ of the measurement period, respectively (Conway et al., 2015), they were responsible for 30 and $50 \%$ of total melt, respectively, simply because melt occurred more frequently in overcast conditions.

When all melting periods were considered together $(42 \%$ of measurement period), SWnet made the largest contribution to QM, with QS and QL together contributing a little over one third and $\mathrm{QR}$ providing a non-negligible fraction (Table 6). On average, LWnet and QC were energy sinks during melting periods. Considering the average SEB terms during all periods, a shift towards QS at the expense of Rnet
Table 7. The $\Delta$ SMB ( $\mathrm{mm}^{\text {w.e. }} \mathrm{yr}^{-1}$ ) to perturbations in surface climate and short-wave radiation terms. While the values shown are the average change in SMB per year for both positive and negative perturbations in each climate variable, for clarity, $\triangle \mathrm{SMB}$ is expressed as the SMB response to an increase in a given input variable or parameter.

\begin{tabular}{lr}
\hline Variable and perturbation & $\Delta \mathrm{SMB}$ \\
\hline$T_{\mathrm{a}}+1 \mathrm{~K}$ & -2065 \\
$P_{\text {scaled }}+20 \%$ & +770 \\
$\mathrm{RH}+10 \%$ & -380 \\
$U+1 \mathrm{~m} \mathrm{~s}^{-1}$ & -790 \\
$\alpha+0.1$ & +1220 \\
Solar constant $-6 \%$ & -260 \\
$k+0.17$ & -740 \\
\hline
\end{tabular}

was observed, due to the inclusion of non-melting clear-sky periods where negative LWnet was largely balanced by QS.

\subsection{Sensitivity of SMB to surface climate}

Model runs with SEBpr over the sensitivity period (see Sect. 2.4) highlight the large sensitivity of SMB to $T_{\mathrm{a}}$ (Table 7). The mass-balance sensitivity $(\triangle \mathrm{SMB})$ is defined as the average change in SMB per annum for both positive and negative perturbations in each climate variable. For clarity, $\triangle \mathrm{SMB}$ is expressed as the SMB response to an increase in a given input variable or parameter. The modest change in SMB to $P_{\text {scaled }} \pm 20 \%$ indicates that an extremely large increase in precipitation would be needed to offset the mass loss associated with moderate atmospheric warming. Increased relative humidity induces a small mass loss, due to increased LW $\downarrow$ and QL. Similarly, a mass loss of $790 \mathrm{~mm}$ w.e. $\mathrm{yr}^{-1}$ occurs for a $1 \mathrm{~m} \mathrm{~s}^{-1}$ increase in $U$, due to an increased contribution of turbulent heat fluxes to melt. The $\triangle$ SMB to terms controlling SWnet is high, with $\alpha \pm 0.1$ inducing over half the SMB response of $T_{\mathrm{a}} \pm 1 \mathrm{~K}$ (Table 7). Variations in the cloud extinction coefficient $(k)$, within the uncertainty range of the radiation scheme optimization (Conway et al., 2015), induce large changes in SMB, emphasizing the important contribution of SWnet to melt during overcast conditions (Table 6). A $6 \%$ decrease in $\mathrm{SW}_{\mathrm{TOA}}$ (the ap- 
Table 8. Cumulative sum of SMB terms for selected runs of SEBpr over the 2-year sensitivity period. All units are in mm w.e., except for $\Delta$ which is in mm w.e. $\mathrm{K}^{-1} \mathrm{yr}^{-1}$.

\begin{tabular}{lrrrrrr}
\hline Scenario & SMB & Snowfall & Melt & Sublimation & Deposition & Refreezing \\
\hline$+1 \mathrm{~K}$ & -9181 & 3900 & 13064 & 32 & 134 & 85 \\
$-1 \mathrm{~K}$ & -920 & 5670 & 6692 & 38 & 135 & 198 \\
$\Delta\left(\mathrm{mm}\right.$ w.e. $\left.\mathrm{K}^{-1} \mathrm{yr}^{-1}\right)$ & -2065 & 443 & -1593 & 2 & 0 & 28 \\
\hline
\end{tabular}

Table 9. Mean SEB terms $\left(\mathrm{W} \mathrm{m}^{-2}\right.$ ) during melting periods in the $+1 \mathrm{~K}$ (a) and $-1 \mathrm{~K}$ (b) perturbation runs of SEBpr. Also shown are mean SEB terms $\left(\mathrm{W} \mathrm{m}^{-2}\right)$ in the $-1 \mathrm{~K}$ perturbation run, for the same periods as (a), i.e. melting periods in the $+1 \mathrm{~K}$ perturbation run (c), and the increases $\left(\mathrm{W} \mathrm{m}^{-2}\right)$ between each scenario $(\mathbf{d}, \mathbf{e})$. The percentage contribution of each flux to QM, or the increase in QM, is given in parentheses. The percentage contribution of each flux to $\triangle \mathrm{SMB}$ is given in the last row (f).

\begin{tabular}{lllllllll}
\hline Scenario & SWnet & LWnet & Rnet & QS & QL & QR & QC & QM \\
\hline (a) +1 K melting periods & $89(62)$ & $-4(-3)$ & $85(59)$ & $37(26)$ & $19(14)$ & $5(3)$ & $-2(-1)$ & 144 \\
(b) -1 K melting periods & $70(68)$ & $-9(-8)$ & $61(60)$ & $28(27)$ & $11(11)$ & $4(4)$ & $-2(-2)$ & 103 \\
(c) -1 K for same periods as (a) & $56(76)$ & $-13(-17)$ & $43(59)$ & $23(32)$ & $7(9)$ & $3(4)$ & $-2(-2)$ & 74 \\
\hline (d) Increase from (b) to (a) & $19(46)$ & $5(11)$ & $23(57)$ & $9(22)$ & $8(20)$ & $1(2)$ & $0(0)$ & 41 \\
(e) Increase from (c) to (a) & $33(47)$ & $8(12)$ & $41(59)$ & $14(20)$ & $13(18)$ & $2(3)$ & $0(0)$ & 70 \\
(f) Contribution to $\Delta$ SMB & $36 \%$ & $9 \%$ & $45 \%$ & $15 \%$ & $14 \%$ & $2 \%$ & $0 \%$ & $77 \%$ \\
\hline
\end{tabular}

proximate change in the solar constant during the last 10000 years) results in only a modest mass loss.

To examine how the large $\triangle \mathrm{SMB}$ to $T_{\mathrm{a}}$ is expressed, a breakdown of SMB terms was constructed for the $+1 \mathrm{~K}$ and $-1 \mathrm{~K}$ perturbation runs (Table 8 ). A change in snowfall accounts for $21 \%$ of $\triangle \mathrm{SMB}$, while a small change in refreezing $(2 \%)$ and a dominant change in melt $(77 \%)$ account for the remainder. Changes in deposition and sublimation are negligible. It is worth clarifying here that changes in snowfall resulting from the perturbations in $T_{\mathrm{a}}$ in this analysis are due solely to changes in the fraction of precipitation falling as snow versus rain. This is distinct from the atmospheric feedback between air temperature and precipitation that can result in increased accumulation due to enhanced precipitation rates in a warmer climate (e.g. Box et al., 2012). The temperate nature of the glacier SBL in the vicinity of $\mathrm{AWS}_{\text {glacier }}$ increases the $\triangle \mathrm{SMB}$ to $T_{\mathrm{a}}$, as most precipitation falls within a few degrees of the rain/snow threshold and snowfall can occur at any time of the year (Cullen and Conway, 2015). Indeed, despite the large ablation at $\mathrm{AWS}_{\text {glacier }}$ over the 22month measurement period ( $>9 \mathrm{~m}$ w.e.), a decrease in $T_{\mathrm{a}}$ of $1.3 \mathrm{~K}$ would be sufficient to produce a net zero SMB.

The change in melt between $T_{\mathrm{a}}$ perturbation runs can be attributed to SEB components whose magnitude is either directly dependent on $T_{\mathrm{a}}$ (i.e. $\mathrm{LW} \downarrow, \mathrm{QS}, \mathrm{QL}$, and $\mathrm{QR}$ ), or indirectly altered by changes to melt and/or snowfall that alter albedo (i.e. SWnet). Table 9 shows mean SEB components for each $T_{\mathrm{a}}$ perturbation run. The most striking feature is that while a $100 \%$ increase in melt occurs between $-1 \mathrm{~K}$ and $+1 \mathrm{~K}$ runs (Table 8), there is only a $40 \%$ increase in QM during melt (Table 9, a and $b$ final column). The majority of increased melt is due to a large increase in the fraction of time melt occurs, from 34 to $48 \%$ of all periods. Thus, a better indication of the contribution of each SEB term to $\triangle \mathrm{SMB}$ can be found by examining the change in SEB terms between runs for the melting periods in the $+1 \mathrm{~K}$ run (Table 9e). By multiplying the contribution of each SEB term to the increase in melt by the fraction melt contributes to the total $\triangle \mathrm{SMB}$ (77\%; Table 8), we find the contribution of each SEB term to the $\triangle \mathrm{SMB}$ (Table 9f). SWnet makes the largest contribution to the increase in melt and accounts for over one-third of the $\triangle \mathrm{SMB}$. The turbulent heat fluxes, QS and QL, together account for less than one-third of the $\triangle \mathrm{SMB}$, while LWnet and $\mathrm{QR}$ make smaller contributions. Thus, changes in QM that are directly dependent on $T_{\mathrm{a}}$ contribute less than half of the $\triangle \mathrm{SMB}$, while changes in snow accumulation and the albedo feedback account for the majority. Given the covariance of cloudiness and SEB terms shown in Sect. 3.3 and the obvious link between cloudiness and precipitation, further examination of the interplay between cloudiness and $\triangle \mathrm{SMB}$ is made in the following section.

\subsection{Impact of clouds on SMB sensitivity}

To begin to describe the influence of cloud cover on the relationship between SMB and $T_{\mathrm{a}}$, the amount of melt that occurred under clear-sky, partial cloud, and overcast conditions was calculated for each $T_{\mathrm{a}}$ perturbation run (Fig. 8). Overcast periods exhibit the largest change in melt between $T_{\mathrm{a}}$ perturbation runs, accounting for $50 \%$ of the $\Delta \mathrm{SMB}$ to $T_{\mathrm{a}}$. Clear-sky and partial cloud conditions show more modest changes in melt and account for 29 and $21 \%$ of the $\triangle \mathrm{SMB}$, respectively. By calculating the mean $\triangle \mathrm{SMB}$ in clear-sky 


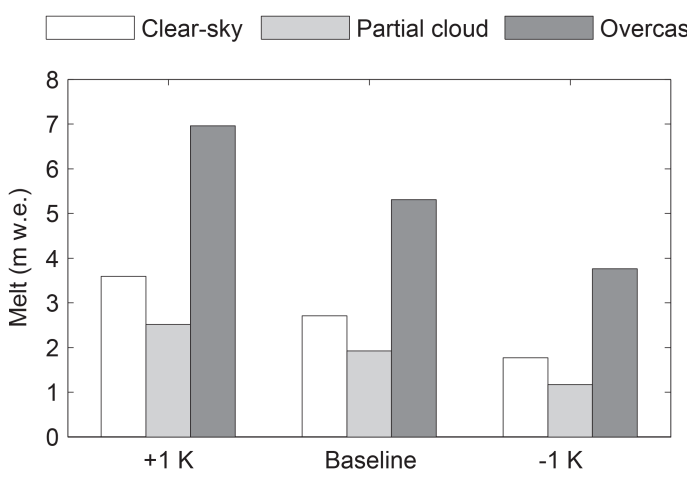

Figure 8. Total surface melt in each cloud cover category for baseline and climate perturbation scenarios.

and overcast conditions for each month, a distinct seasonal cycle as well as a clear dependence on cloudiness emerged (Fig. 9). In general, the $\triangle \mathrm{SMB}$ is greatly reduced during winter months, as $T_{\mathrm{a}}$ is well below $T_{\mathrm{r} / \mathrm{s}}$ and ablation is minimal at $\mathrm{AWS}_{\text {glacier. }}$ Overcast conditions almost always produce higher $\triangle \mathrm{SMB}$ than clear skies, especially during spring and autumn. A peak in $\triangle \mathrm{SMB}$ during October is associated with a higher fraction of marginal melt conditions and average $T_{\mathrm{a}}$ around $T_{\mathrm{r} / \mathrm{s}}$. From May to October (inclusive) $\Delta \mathrm{SMB}$ in clear-sky conditions is minimal. January and February, however, show large $\triangle \mathrm{SMB}$ in clear-sky conditions, as the magnitude of SWnet during these months is greatly influenced by changes in albedo driven by the timing of the transition to an ice surface and occurrence of summer snowfall. This albedo feedback occurs as increased $T_{\mathrm{a}}$ decreases the fraction of precipitation falling as snow, thus decreasing the duration of snow cover and reducing summer snowfall.

In order to remove the albedo feedback, further runs of SEBpr were made for -1 and $+1 \mathrm{~K}$ scenarios. By using measured albedo and perturbing $T_{\mathrm{r} / \mathrm{s}}$ by the same magnitude as $T_{\mathrm{a}}$, both accumulation and SWnet remained consistent between these runs and the resulting $\triangle \mathrm{SMB}$ (direct) is due to only changes in QM directly caused by increased $T_{\mathrm{a}}$ (Fig. 9, dashed lines). The divergence of full and direct $\triangle \mathrm{SMB}$ in clear-sky conditions confirmed that changes in melt due to an albedo feedback dominate clear-sky $\triangle \mathrm{SMB}$, especially in the summer. In overcast conditions, the direct $\triangle \mathrm{SMB}$ is somewhat less than the full $\triangle \mathrm{SMB}$ in each month, as periods with altered snowfall are removed. Still, the direct $\Delta \mathrm{SMB}$ remained approximately twice as large as that in clear-sky conditions through each month. Thus, it is evident that cloudy conditions have a much stronger influence on $\triangle \mathrm{SMB}$ to $T_{\mathrm{a}}$ than clear-sky conditions, with an increased $\triangle \mathrm{SMB}$ in cloudy conditions being due to changes in both snowfall and melt, and being strongest in the spring and autumn seasons.

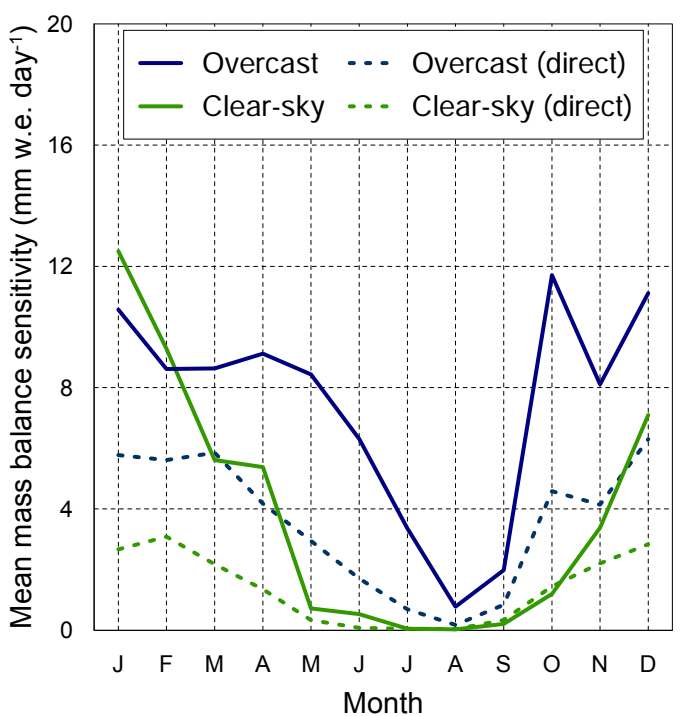

Figure 9. The mean daily mass-balance sensitivity $(\triangle \mathrm{SMB})$ to a $1 \mathrm{~K}$ change in $T_{\mathrm{a}}$, separated into clear-sky (green) and overcast (blue) conditions, in each month of the year. The dashed lines show $\triangle \mathrm{SMB}$ resulting from only a direct change in $\mathrm{QM}$, which was derived from a further model run using measured albedo and perturbing $T_{\mathrm{r} / \mathrm{s}}$ with $T_{\mathrm{a}}$. The positive values indicate mass loss for increased $T_{\mathrm{a}}$.

\section{Discussion}

\subsection{Cloud impacts on SBL and SEB}

The large difference in SEB terms between clear and overcast conditions seen in these results is driven in large part by changes in $e_{\mathrm{a}}$, rather than changes in $T_{\mathrm{a}}$. The increase in $e_{\mathrm{a}}$ in overcast conditions is enabled by the poor association of $T_{\mathrm{a}}$ and cloud cover, in addition to the obvious covariance between RH and cloudiness. That $T_{\mathrm{a}}$ is not markedly decreased in overcast conditions differs from similar studies in the European Alps (e.g. Pellicciotti et al., 2005) and Norway (Giesen et al., 2008), and is indicative of the maritime setting where air mass properties, rather than a positive association between summertime insolation and air temperature (Sicart et al., 2008), are the primary control on SBL variations (Cullen and Conway, 2015). The availability of moist and relatively warm air masses to the glacier surface also creates positive LWnet in overcast conditions, which along with increases in QL, allows for steady melt through much greater periods of time. Consequently, average daily melt rates are similar in clear-sky and overcast conditions, again in contrast with studies in the European Alps that show increased melt in clear-sky conditions (Pellicciotti et al., 2005). Glaciers in Norway (Giesen et al., 2008) show higher total melt during overcast conditions due to higher $U$ that increase turbulent heat fluxes during frequent cloud cover. While increased $U$ and turbulent heat fluxes are observed for the largest melt events on Brewster Glacier (Gillett and Cullen, 2011), mean $U$ was not well differentiated by cloudiness over the mea- 
surement period, leaving $T_{\mathrm{a}}$ and $e_{\mathrm{a}}$ as the primary controls of mean QS and QL, respectively.

While LWnet was substantially increased during overcast periods, a "radiation paradox" (Ambach, 1974) does not occur during most of the melt season in the ablation zone of Brewster Glacier, due to high $\mathrm{SW}_{\mathrm{TOA}}$, large cloud extinction coefficients, and a smaller difference in sky emissivity in clear-sky and overcast conditions at this mid-latitude location. In contrast, maritime sites on the melting margin of the Greenland ice sheet show that clouds act to increase Rnet throughout the melt season at a range of elevations (van den Broeke et al., 2008a). At the lowest site where the surface is melting over $80 \%$ of the summer period, the presence of a strong 'radiation paradox' implies that melt rates are higher during overcast conditions, which is supported by the absence of increased summer melt during more frequent clear-sky conditions (van den Broeke et al., 2011). The lack of a "radiation paradox" during the summer months on the lower part of Brewster Glacier emphasizes the role of air mass properties that are advected from the surrounding ocean areas in maintaining $T_{\mathrm{a}}$ and enabling enhanced LWnet and QL during overcast periods. In the same way, during the transition periods, especially in the autumn, increased melt rates were enabled by a "radiation paradox".

\subsection{Cloud impacts on SMB sensitivity}

The increased sensitivity of SMB to $T_{\mathrm{a}}$ in overcast conditions may help explain some of the high sensitivity of SMB to $T_{\mathrm{a}}$ in the Southern Alps. Importantly, average melt is not reduced in overcast conditions and cloud cover is frequent in the Southern Alps. Therefore, a large fraction of melt occurs in overcast conditions which the results from this research suggest are more sensitive to changes in $T_{\mathrm{a}}$. In conjunction with increased $e_{\mathrm{a}}$, clouds extend melt into periods of marginal melt that are more sensitive to changes in $T_{\mathrm{a}}$, as well as being strongly associated with frequent precipitation around $T_{\mathrm{r} / \mathrm{s}}$. Indeed, roughly half of the sensitivity to $T_{\mathrm{a}}$ is due to an albedo feedback, in line with previous work in the Southern Alps (Oerlemans, 1997), emphasizing that turbulent heat fluxes play a secondary role, despite the assertions of recent palaeoclimatic research (Putnam et al., 2012). In addition, the largest melt events - which constitute a large fraction of melt over a season (Gillett and Cullen, 2011) - are associated with overcast conditions and contribute to proportionally larger changes in melt. Thus, air mass variability, in particular air temperature associated with high water vapour content, appears to be the primary control on melt during the summer ablation season.

Aside from their role in the $\triangle \mathrm{SMB}$ to $T_{\mathrm{a}}$, the contribution of turbulent heat fluxes to melt may have been overstated in a number of studies, at the expense of Rnet. In fact, the contribution of Rnet to ablation in the present study is similar to that found over mixed snow/ice ablation surfaces in Norway (68\%; Giesen et al., 2008) and coastal Greenland ( 70\%
(S6); van den Broeke et al., 2008b), and similar to that found for a névé area in New Zealand (Kelliher et al., 1996). There are a number of possible reasons for the deviation of the current study from previously reported values for glacier surfaces in the Southern Alps (e.g. Marcus et al., 1985; Hay and Fitzharris, 1988; Ishikawa et al., 1992; Anderson et al., 2010). Firstly, in earlier studies simplifications were usually made in the calculation of the turbulent heat fluxes, including the assumption that the surface is always melting. Secondly, average SEB terms were traditionally reported for the entire study period, rather than only those during periods of melt. Table 6 clearly shows full-period average SEB terms are biased towards QS, as non-melting nocturnal and winter periods are included. These periods have higher values of QS, which serve to balance negative LWnet. Lastly, a number of the studies have been conducted in low elevation areas, where turbulent heat fluxes are increased, despite these areas being atypical in the Southern Alps (mean elevation of glacier termini > $1500 \mathrm{~m}$ a.s.1.; Hoelzle et al., 2007).

\subsection{Implications for modelling glacier-climate interactions}

While the present study does not make an assessment of glacier-wide $\triangle \mathrm{SMB}$ and therefore is somewhat limited in discussing atmospheric controls on glacier fluctuations, it shows that the response of glacier melt to changes in $T_{\mathrm{a}}$ can be altered by clouds. This has two important implications for our understanding of glacier climate interactions.

Firstly, efforts to characterize glacier-climate connections need to consider the effects of changing atmospheric moisture on melt rate as well as accumulation. New avenues to model glacier melt with enhanced temperature index models (TIMs) or other empirical descriptions of the temperaturedependent fluxes (e.g. Giesen and Oerlemans, 2012) need to consider the variance of atmospheric moisture with respect to melt. This is both due to the strong increase in LW $\downarrow$ by clouds, but also the association with increased positive QL in moist environments. This may be important for other maritime areas, as well as the Southern Alps where TIMs have already been shown to break down in large melt events (Cutler and Fitzharris, 2005; Gillett and Cullen, 2011). The use of coupled glacier-mass-balance-atmospheric models also present an avenue to represent past and future interactions in a physically realistic way (e.g. Collier et al., 2013).

Secondly, it follows that a change in the frequency of cloud cover or synoptic regime may enhance/dampen the SMB response to $T_{\mathrm{a}}$. For example, a decrease in $\triangle \mathrm{SMB}$ from west to east across the Southern Alps is likely, in association with the strong gradient of precipitation and cloudiness (Uddstrom et al., 2001). It is enticing to reduce the relationship between glacier mass balance and climate to the main causal mechanisms (i.e. temperature/precipitation paradigm). However, there is also the possibility that changes in atmospheric circulation coincident with changes in state variables in the past 
(i.e. during the last glacial maximum; Drost et al., 2007; Ackerley et al., 2011) may alter empirical relationships (i.e. TIMs) informed during the present climate, altering the climate signals derived from glacier fluctuations. For the Southern Alps, the most compelling analysis of the controls on SMB points to changes in the regional circulation patterns (Fitzharris et al., 2007), which are in turn associated with strong changes in both air mass properties and cloudiness (Hay and Fitzharris, 1988). Thus, it is likely that average relationships between melt and air temperature may indeed be changed if a shift to drier or wetter conditions is experienced.

The high fraction of melt due to SWnet and large contribution of an albedo feedback to $\triangle \mathrm{SMB}$ also implies that local or regional influences on albedo may have an important role in modifying melt rate as seen in other areas (Oerlemans et al., 2009). Indeed, the LGM period shows higher rates of glacial loess deposition in New Zealand (Eden and Hammond, 2003); thus the role of terrigenous dust in modifying glacier ablation rates during the onset of glacier retreat (e.g. Peltier and Marshall, 1995) is a topic that should be explored further in the context of the Southern Alps.

\section{Conclusions}

We have presented a validated time series of SEB/SMB in the ablation zone of a glacier in the Southern Alps of New Zealand during two annual cycles. High-quality radiation data allowed a careful evaluation of the magnitude of SEB terms, as well as the selection of clear-sky and overcast conditions. An analysis of SBL climate and SEB showed a fundamental change in SEB with cloudiness that was driven by an increase in effective sky emissivity and vapour pressure at the glacier surface. The only slightly diminished $T_{\mathrm{a}}$ during overcast periods created positive LWnet and also allowed both QS and QL to remain large and directed toward the surface. This created a strong increase in the fraction of time the surface was melting in overcast conditions, which led to a similar average melt rate in clear-sky and overcast conditions. Given the frequent cloud cover at the site, cloudy periods accounted for a majority of the melt observed, especially during autumn when SWnet inputs were lower.

A parameterization of radiation components allowed the sensitivity of SMB to independent changes in SBL climate and short-wave radiation components to be assessed. The large sensitivity of SMB to $T_{\mathrm{a}}$ was expressed primarily through changes in the partitioning of precipitation into snowfall and rainfall, as well as the associated albedo feedback. The remainder of this sensitivity was due to changes in the fraction of time the surface was melting and changes in the magnitude of QS, QL, LWnet, and QR (in that order of importance). We also presented a novel analysis to show that the sensitivity of SMB to $T_{\mathrm{a}}$ diverged strongly when partitioned into clear-sky and overcast periods. Enhanced sensitivity was found in overcast periods due to the occurrence of precipitation and an ability for melt to be produced over larger fractions of time. Increased sensitivity during overcast periods may explain some of the high sensitivity of SMB in the Southern Alps, and raises the possibility that the response of SMB to $T_{\mathrm{a}}$ in the past or future may be altered by changing synoptic patterns that are strongly associated with cloud cover. Thus, it highlights the need to include the effect of atmospheric moisture (vapour, cloud, and precipitation) on both melt and accumulation processes when modelling glacier-climate interactions.

Acknowledgements. Funding from a University of Otago Research Grant (ORG10-10793101RAT) supported N. Cullen's contribution to this research. The research was also supported in part by the National Institute of Water and Atmospheric Research project "Climate Present and Past". The Department of Conservation supported this research under concession OT-32299-OTH. We thank T. Mölg for providing model code and for many helpful discussions on model development, as well as P. Sirguey and W. Colgan for helpful discussions on the Monte Carlo approach. D. Howarth and N. McDonald provided careful technical support for the field measurements. We thank the numerous people who have contributed to the ongoing field program at Brewster Glacier. We thank the editor and reviewers for their helpful comments.

Edited by: E. Larour

\section{References}

Ackerley, D., Lorrey, A., Renwick, J. A., Phipps, S. J., Wagner, S., Dean, S., Singarayer, J., Valdes, P., Abe-Ouchi, A., Ohgaito, R., and Jones, J. M.: Using synoptic type analysis to understand New Zealand climate during the Mid-Holocene, Clim. Past, 7, 11891207, doi:10.5194/cp-7-1189-2011, 2011.

Ambach, W.: The influence of cloudiness on the net radiation balance of a snow surface with high albedo, J. Glaciol., 13, 73-84, 1974.

Anderson, B., Lawson, W., Owens, I., and Goodsell, B.: Past and future mass balance of "Ka Roimata o Hine Hukatere" Franz Josef Glacier, New Zealand, J. Glaciol., 52, 597-607, doi:10.3189/172756506781828449, 2006.

Anderson, B., Mackintosh, A., Stumm, D., George, L., Kerr, T., Winter-Billington, A., and Fitzsimons, S.: Climate sensitivity of a high-precipitation glacier in New Zealand, J. Glaciol., 56, 114128, doi:10.3189/002214310791190929, 2010.

Blonquist, J. M., Tanner, B. D., and Bugbee, B.: Evaluation of measurement accuracy and comparison of two new and three traditional net radiometers, Agr. For. Meteorol., 149, 1709-1721, doi:10.1016/j.agrformet.2009.05.015, 2009.

Box, J. E., Fettweis, X., Stroeve, J. C., Tedesco, M., Hall, D. K., and Steffen, K.: Greenland ice sheet albedo feedback: thermodynamics and atmospheric drivers, The Cryosphere, 6, 821-839, doi:10.5194/tc-6-821-2012, 2012.

Chinn, T., Fitzharris, B. B., Willsman, A., and Salinger, M. J.: Annual ice volume changes 1976-2008 for the New Zealand Southern Alps, Global Planet. Change, 92-93, 105-118, doi:10.1016/j.gloplacha.2012.04.002, 2012. 
Collier, E., Mölg, T., Maussion, F., Scherer, D., Mayer, C., and Bush, A. B. G.: High-resolution interactive modelling of the mountain glacier-atmosphere interface: an application over the Karakoram, The Cryosphere, 7, 779-795, doi:10.5194/tc-7-7792013, 2013.

Conway, J. P.: Constraining Cloud and Airmass Controls on the Surface Energy and Mass Balance of Brewster Glacier, Southern Alps of New Zealand (Thesis, Doctor of Philosophy), University of Otago, http://hdl.handle.net/10523/4432 (last access: 1 December 2014), 2013.

Conway, J. P. and Cullen, N. J.: Constraining turbulent heat flux parameterization over a temperate maritime glacier in New Zealand, Ann. Glaciol., 54, 41-51, doi:10.3189/2013AoG63A604, 2013.

Conway, J. P., Cullen, N. J., Spronken-Smith, R. A., and Fitzsimons, S. J.: All-sky radiation over a glacier surface in the Southern Alps of New Zealand: characterizing cloud effects on incoming shortwave, longwave and net radiation, Int. J. Climatol., 35, 699-713, doi:10.1002/joc.4014, 2015.

Cullen, N. J. and Conway, J. P.: A 22-month record of surface meteorology and energy balance from the ablation zone of Brewster Glacier, New Zealand, J. Glaciol., 61, 931-946, doi:10.3189/2015JoG15J004, 2015.

Cutler, E. S. and Fitzharris, B.: Observed surface snowmelt at high elevation in the Southern Alps of New Zealand, Ann. Glaciol., 40, 163-168, doi:10.3189/172756405781813447, 2005.

Drost, F. and Renwick, J.: Simulation of New Zealand's climate using a high-resolution nested regional climate model, Int. J. Climatol., 1169, 1153-1169, doi:10.1002/joc.1461, 2007.

Dürr, B. and Philipona, R.: Automatic cloud amount detection by surface longwave downward radiation measurements, J. Geophys. Res., 109, D05201, doi:10.1029/2003JD004182, 2004.

Eden, D. N. and Hammond, A. P.: Dust accumulation in the New Zealand region since the last glacial maximum, Quat. Sci. Rev., 22, 2037-2052, doi:10.1016/S0277-3791(03)00168-9, 2003.

Fitzharris, B. B., Clare, G. R., and Renwick, J. A.: Teleconnections between Andean and New Zealand glaciers, Global Planet. Change, 59, 159-174, doi:10.1016/j.gloplacha.2006.11.022, 2007.

Giesen, R. H. and Oerlemans, J.: Calibration of a surface mass balance model for global-scale applications, The Cryosphere, 6 , 1463-1481, doi:10.5194/tc-6-1463-2012, 2012.

Giesen, R. H., van den Broeke, M. R., Oerlemans, J., and Andreassen, L. M.: Surface energy balance in the ablation zone of Midtdalsbreen, a glacier in southern Norway: Interannual variability and the effect of clouds, J. Geophys. Res., 113, 1-17, doi:10.1029/2008JD010390, 2008.

Gillett, S. and Cullen, N. J.: Atmospheric controls on summer ablation over Brewster Glacier, New Zealand, Int. J. Climatol., 31, 2033-2048, doi:10.1002/joc.2216, 2011.

Hay, J. E. and Fitzharris, B. B.: The synoptic climatology of ablation on a New Zealand glacier, J. Climatol., 8, 201-215, doi:10.1002/joc.3370080207, 1988.

Hoelzle, M., Chinn, T., Stumm, D., Paul, F., Zemp, M., and Haeberli, W.: The application of glacier inventory data for estimating past climate change effects on mountain glaciers: A comparison between the European Alps and the Southern Alps of New Zealand, Global Planet. Change, 56, 69-82, doi:10.1016/j.gloplacha.2006.07.001, 2007.
Ishikawa, N., Owens, I. F., and Sturman, A. P.: Heat balance characteristics during find periods on the lower parts of the Franz Josef Glacier, South Westland, New Zealand, Int. J. Climatol., 12, 397-410, 1992.

Jost, G., Moore, R. D., Menounos, B., and Wheate, R.: Quantifying the contribution of glacier runoff to streamflow in the upper Columbia River Basin, Canada, Hydrol. Earth Syst. Sci., 16, 849-860, doi:10.5194/hess-16-849-2012, 2012.

Kaser, G., Cogley, J. G., Dyurgerov, M. B., Meier, M. F., and Ohmura, A.: Mass balance of glaciers and ice caps: Consensus estimates for 1961-2004, Geophys. Res. Lett., 33, L19501, doi:10.1029/2006GL027511, 2006.

Kelliher, F. M., Owens, I. F., Sturman, A. P., Byers, J. N., Hunt, J. E., and McSeveny, T. M.: Radiation and abaltion on the neve of Franz Josef Glacier, J. Hydrol., 35, 129-148, 1996.

Konzelmann, T., Van de Wal, R., Greuell, W., Bintanja, R., Henneken, E., and Abe-Ouchi, A.: Parameterization of global and longwave incoming radiation for the Greenland Ice Sheet, Global Planet. Change, 9, 143-164, 1994.

Kuipers Munneke, P., Reijmer, C. H., and van den Broeke, M. R.: Assessing the retrieval of cloud properties from radiation measurements over snow and ice, Int. J. Climatol., 31, 756-769, doi:10.1002/joc.2114, 2011.

Lorrey, A., Fowler, A. M., and Salinger, J.: Regional climate regime classification as a qualitative tool for interpreting multiproxy palaeoclimate data spatial patterns: A New Zealand case study, Palaeogeogr. Palaeoclimatol. Palaeoecol., 253, 407-433, doi:10.1016/j.palaeo.2007.06.011, 2007.

Machguth, H., Purves, R. S., Oerlemans, J., Hoelzle, M., and Paul, F.: Exploring uncertainty in glacier mass balance modelling with Monte Carlo simulation, The Cryosphere, 2, 447485, doi:10.5194/tcd-2-447-2008, 2008.

Marcus, M. G., Moore, R. D., and Owens, I. F.: Short-term estimates of surface energy transfers and ablation on the lower Franz Josef Glacier, South Westland, New Zealand, New Zeal. J. Geol. Geophys., 28, 559-567, 1985.

Mölg, T., Cullen, N., Hardy, D. R., Kaser, G., and Klok, L.: Mass balance of a slope glacier on Kilimanjaro and its sensitivity to climate, Int. J. Climatol., 28, 881-892, doi:10.1002/joc1589, 2008.

Mölg, T., Cullen, N. J., Hardy, D. R., Winkler, M., and Kaser, G.: Quantifying Climate Change in the Tropical Midtroposphere over East Africa from Glacier Shrinkage on Kilimanjaro, J. Clim., 22, 4162-4181, doi:10.1175/2009JCLI2954.1, 2009a.

Mölg, T., Cullen, N., and Kaser, G.: Solar radiation, cloudiness and longwave radiation over low-latitude glaciers: implications for mass-balance modelling, J. Glaciol., 55, 292-302, 2009 b.

Mölg, T., Großhauser, M., Hemp, A., Hofer, M., and Marzeion, B.: Limited forcing of glacier loss through land-cover change on Kilimanjaro, Nat. Clim. Chang., 2, 254-258, doi:10.1038/nclimate1390, 2012.

Oerlemans, J.: Climate Sensitivity of Franz Josef Glacier, New Zealand, as Revealed by Numerical Modeling, Arct. Alp. Res., 29, 233-239, 1997.

Oerlemans, J.: Extracting a climate signal from 169 glacier records, Science, 308, 675-677, doi:10.1126/science.1107046, 2005.

Oerlemans, J.: The Microclimate of Valley Glaciers, Igitur, Utrecht University, the Netherlands, 122-124, 2010. 
Oerlemans, J. and Knap, W. H.: A 1 year record of global radiation and albedo in the ablationzone of Morteratschgletscher, Switzerland, J. Glaciol., 44, 231-238, 1998.

Oerlemans, J., Giesen, R. H., and Van den Broeke, M. R.: Retreating alpine glaciers: increased melt rates due to accumulation of dust (Vadret da Morteratsch, Switzerland), J. Glaciol., 55, 729-736, doi:10.3189/002214309789470969, 2009.

Pellicciotti, F., Brock, B., Strasser, U., Burlando, P., Funk, M., and Corripio, J.: An enhanced temperature-index glacier melt model including the shortwave radiation balance: development and testing for Haut Glacier d'Arolla, Switzerland, J. Glaciol., 51, 573587, doi:10.3189/172756505781829124, 2005.

Peltier, W. R. and Marshall, S.: Coupled energy balance/ice-sheet model simulations of the glacial cycle: A possible connection between terminus and terrigenous dust, J. Geophys. Res., 100, 14269-14289, 1995.

Putnam, A. E., Schaefer, J. M., Denton, G. H., Barrell, D. J. A., Finkel, R. C., Andersen, B. G., Schwartz, R., Chinn, T. J. H., and Doughty, A. M.: Regional climate control of glaciers in New Zealand and Europe during the pre-industrial Holocene, Nat. Geosci., 5, 627-630, doi:10.1038/ngeo1548, 2012.

Sicart, J. E., Hock, R., and Six, D.: Glacier melt, air temperature, and energy balance in different climates: The Bolivian Tropics, the French Alps, and northern Sweden, J. Geophys. Res., 113, D24113, doi:10.1029/2008JD010406, 2008.

Sicart, J. E., Hock, R., Ribstein, P., and Chazarin, J. P.: Sky longwave radiation on tropical Andean glaciers?: parameterization and sensitivity to atmospheric variables, J. Glaciol., 56, 854-860, 2010.

Tait, A. B. and Fitzharris, B. B.: Relationships between New Zealand rainfall and south-west Pacific pressure patterns, Int. J. Climatol., 18, 407-424, doi:10.1002/(SICI)10970088(19980330)18:4<407::AID-JOC256>3.0.CO;2-S, 1998.
Uddstrom, M. J., McGregor, J. A., Gray, W. R., and Kidson, J. W.: A High-Resolution Analysis of Cloud Amount and Type over Complex Topography, J. Appl. Meteorol., 40, 16-33, 2001.

Ummenhofer, C. C. and England, M. H.: Interannual Extremes in New Zealand Precipitation Linked to Modes of Southern Hemisphere Climate Variability, J. Clim., 20, 5418-5440, doi:10.1175/2007JCLI1430.1, 2007.

Van den Broeke, M. R., Van As, D., Reijmer, C., and Van de Wal, R.: Assessing and Improving the Quality of Unattended Radiation Observations in Antarctica, J. Atmos. Ocean. Technol., 21, 1417-1431, doi:10.1175/15200426(2004)021<1417:AAITQO>2.0.CO;2, 2004.

Van den Broeke, M., Reijmer, C., Van As, D., and Boot, W.: Daily cycle of the surface energy balance in Antarctica and the influence of clouds, Int. J. Climatol., 26, 1587-1605, doi:10.1002/joc.1323, 2006.

Van den Broeke, M. R., Smeets, C. J. P. P., Ettema, J., and Kuipers Munneke, P.: Surface radiation balance in the ablation zone of the west Greenland ice sheet, J. Geophys. Res., 113, D13105, doi:10.1029/2007JD009283, 2008a.

Van den Broeke, M., Smeets, P., Ettema, J., van der Veen, C., van de Wal, R., and Oerlemans, J.: Partitioning of melt energy and meltwater fluxes in the ablation zone of the west Greenland ice sheet, The Cryosphere, 2, 179-189, doi:10.5194/tc-2-179-2008, 2008b.

Van den Broeke, M. R., Smeets, C. J. P. P., and van de Wal, R. S. W.: The seasonal cycle and interannual variability of surface energy balance and melt in the ablation zone of the west Greenland ice sheet, The Cryosphere, 5, 377-390, doi:10.5194/tc-5-377-2011, 2011.

Willis, I., Lawson, W., Owens, I., Jacobel, B., and Autridge, J.: Subglacial drainage system structure and morphology of Brewster Glacier, New Zealand, Hydrol. Process., 23, 384-396, doi:10.1002/hyp.7146, 2009. 